\title{
The Effect of Temporal Distance and Social Distance on the Choice of Consumers' Preferences
}

\author{
Yaozhong Liu, Jinjing Xu \\ Management School, Jinan University, Guangzhou, China \\ Email: aitatu@163.com
}

Received 23 January 2015; accepted 9 February 2015; published 12 February 2015

Copyright (C) 2015 by authors and Scientific Research Publishing Inc.

This work is licensed under the Creative Commons Attribution International License (CC BY).

http://creativecommons.org/licenses/by/4.0/

(c) () Open Access

\section{Abstract}

Temporal distance is defined as how much time (e.g., past or future) separates between the perceiver's present time and the target event. Social distance is defined as how distinct is the social target from the perceiver's self (e.g., oneself vs others). The interpretation of events will change as different psychological distance changes (e.g., Temporal Distance, Spatial Distance, Social Distance) and then affect people's reactions, judgment and decision-making. In real life, consumers often have to make a choice between two types of products: one of them is often called the "virtue products", and the other one was accordingly called the "vice products". This study uses experimental methods to explore the influence of temporal distance and social distance on the choice of consumers' preference and obtains the following conclusions: 1) When consumers make choices for themselves, compared to now, they are more inclined to choose the virtue product at a future time; when consumers make choices for others, compared to now, they are more inclined to choose the virtue product at a future time; when consumers make choices now, compared to choose for themselves, they are more inclined to choose virtue products for others; when consumers make choices at a future time, compared to choose for themselves, they are more inclined to choose virtue products for others; 2) The ANOVA of eye movements data on virtue products (i.e., fixation length and fixation count) showed that main effects of temporal distance and social distance were significant, but there was not interaction between both factors.

\section{Keywords}

Temporal Distance, Social Distance, Virtue Products, Vice Products

\section{Introduction}

In the study of consuming behavior, consumers often have to make a choice between two types of products, 
which are the long-term high effectiveness but lower in the short term, or the short-term efficiency but lower effect or even negative (such as harmful to body) in long term. One of them is often called the "virtue products", and the other one was accordingly called the "vice products" [1].

In behavioral research, the virtue products usually include vegetable salad, cereal and other foods of relatively poor taste but good for health, exercises, and educational but boring documentaries. Accordingly, the vice products commonly include pizza, chocolate cake, tobacco and alcoholic beverages, as well as entertainment film. In addition, in previous research, several other groups of words are often used to describe similar concepts, such as hedonic products and utilitarian products [2] [3], "want" items and "should" items [4], high-brow products and low-brow products [5].

Temporal distance is defined as how much time (e.g., past or future) separates between the perceiver's present time and the target event [6]. Read, Loewenstein and Kalyanaraman (1999) found that most of people chose virtue products in instant decision making, and people were more inclined to choose vice-virtue mixed mode to buy products in a sequential decision making, but they would prefer vice products in the instant decision making.

Social distance is defined as how distinct is the social target from the perceiver's self (e.g., oneself vs others) (Bar-Anan, 2006). In daily life, we need not only to make decisions for ourselves, but also to make decisions or to expect decisions for others. Many studies have shown that, in some situations, compared to self-decision, making decision for others indeed showed less contravention of the rational decision-making principles. For example, self-decision in most cases showed choice overload (Polman, 2012) [7], omission bias (Zikmund-Fisher et al., 2006) [8], confirmatory bias and so on about such irrational behaviors (Jonas and Frey, 2003) [9].

According to the Construal Level Theory (CLT), the interpretation of events will change as different psychologically distal targets (e.g., Temporal Distance, Spatial Distance, Social Distance), and then affect people's reactions, judgment and decision-making [10] [11]. People use a more abstract, high construal level when judging, perceiving, and predicting more psychologically distal targets, and they judge more abstract targets as being more psychologically distal. The present research demonstrated that associations between more distance and higher level of construal also existed on a pure conceptual level. When consumers make choice for themselves, they are more inclined to consider specific aspects, and focus on the effectiveness in short term. For example, in food, more attention is focused on the taste and texture for ourselves; on the contrary, for others (psychological distance is farther), the consumers are more inclined to consider abstract aspects, and pay more attention to longterm effect, and focus on health and nutrition. There is a similar phenomenon on temporal distance, compared to in the instant decision, the consumers tended to consider abstract aspect for far future (a week later). Therefore, in the decision-making of consumers' preference, in the different construal level, the role of temporal distance and social distance are different. When different temporal distance (now vs. a week later) combined with different social distance (self vs. a strange young man), the role of social distance and temporal distance may not have played the same equivalence, therefore we can predict:

H1: When consumers make choices for themselves, compared to now, they are more inclined to choose the virtue product at a future time;

H2: When consumers make choices for others, compared to now, they are more inclined to choose the virtue product at a future time;

H3: When consumers make choices at a future time, compared to choose for themselves, they are more inclined to choose virtue products for others;

H4: When consumers make choices now, compared to choose for themselves, they are more inclined to choose virtue products for others.

\section{Method}

\subsection{Participants}

Forty postgraduates from Jinan University (18 males and 22 females; mean age 23.47years old, SD = 1.390) participated in the experiment. All participants' naked-eye vision or corrected vision is greater than 1.0. After the experiment completed, through checking up the accuracy of the data, we found that one participant's data quality below standard, may affect the result of the data, as rejected. Then add 1 subject participated in experiment.

\subsection{Research Design}

The experiment had a $2 \times 2$ two factor completely randomized design, with the first factor is temporal distance 
(now vs. a week later) and the second factor is social distance (yourself vs. a strange young man S). The dependent variable consists of two parts, one part is the selection result of virtue and vice products, the other part is the indexes of eye movements during the reaction, which are fixation length and fixation count.

\subsection{Research Tools}

Tobii T120 Eye Tracker, produced by Tobii pro. The data rate is $120 \mathrm{~Hz}$, the freedom of head movement is $30 \times$ $22 \times 30 \mathrm{~cm}$, the TFT display is 17 TFT, $1280 \times 1024$ pixels, the eye tracking system allows for a large degree of head movement, providing a distraction-free test environment that ensures natural behavior, and therefore valid results. The Tobii T120 Eye Tracker offers a higher tracking frequency for eye tracking studies that require finer gaze-detail data. Using Tobii Studio analysis software, we can design the presentation order of experimental materials, collect eye movement related data at the same time and provide comprehensive analysis tools.

\subsection{Research Materials}

According to our experimental purpose, compiled the consumers’ preferences context under different temporal distance and social distance as experimental materials, we got 4 questions through a pre-test. Each question was divided into four kinds of conditions: now-oneself, a week later-oneself, now-others and a week later-others, so a total of 16 questions as formal experimental materials. Compiled 2 questions which similar to the formal experimental context as practice, so that participants were acquainted with the experimental materials.

Selected 20 participants, from the same group with who would participate in the following main experiment, but do not participate in follow-up experiment. Chocolate cake(vice product) and sugar-free fiber biscuit(virtue product) as an example, they were asked to use Likert7 point scoring method evaluated in "health" and "delicious" two dimensions: 1 = extremely unhealthy, 7 = extremely healthy, $1=$ extremely unpalatable, $7=$ extremely delicious. We found that the score of chocolate cake on the health dimension is 3.33, and sugar-free fiber biscuit is 5.79, sugar-free fiber biscuit's score is significantly higher than chocolate cake $(\mathrm{t}(23)=13.629$, $\mathrm{p}<$ 0.001 ); the score of chocolate cake on the delicious dimension is 5.33, and sugar-free fiber biscuit is 4.46 , chocolate cake's score is significantly higher than sugar-free fiber biscuit's ( $\mathrm{t}(23)=9.559, \mathrm{p}<0.001)$.

Selected 20 participants, from the same group with who would participate in the following main experiment, but do not participate in follow-up experiment. Chocolate cake (vice product) and sugar-free fiber biscuit (virtue product) as an example, they were asked to score on five pictures represent chocolate cake and sugar-free fiber respectively, 1 = totally not represent, 2 = completely represent. Used SPSS19.0 calculated average score of each picture, screened out the highest score of the pictures as the experimental materials, the score of the picture which represents chocolate cake is $6.40 \pm 0.753$, the score of the picture which represents sugar-free fiber biscuit is $6.35 \pm 0.670$.

Through the Tobii Studio compiled experimental procedures and presented the stimulus material in the eye tracker, real-time record indexes of eye movement. Each context question presented in tabular form in the center of the screen, font size is 18, black, Microsoft Yahei Font, character spacing is 1 pound, row spacing is 1 time. The image size is $7.73 \times 10.62 \mathrm{~cm}$, colorful.

\subsection{Research Procedure}

This experiment was conducted at Eye Movement Laboratory of the Jinan University Management Talent Assessment Center (sound insulation, light control). Each time 1 participant, an experimenter was responsible for operating eye tracker and recorded the oral report of selected results. The specific procedures are as follows:

1) Participants enter the lab, and get familiar with the internal environment, avoiding stress, anxiety. Participants sit about $80 \mathrm{~cm}$ in front of the eye tracker and keep eyes on the monitor center.

2) The experimenter introduce the purpose and requirements to participants: "This experiment aims to test people's preferences for products or activities. Before the formal experiment, you will see a red dot, it will randomly appear on the screen, you need to keep track of when you look at it until it appears. Don't swing your body or head drastically, keep calm expression during experiment.”

3) After eye calibration, the display will present instruction: "Hello! Thank you for participating in this experiment, it will present four images, each image includes a table, please read the description in the table, based on the information provided to make a choice, rather than in accordance with your preferences, direct verbal report 
your choice, while keep staring at the screen. Note: in this experiment, there is no correct answer, no time limit. In order to make you familiar with experimental procedures, there are 2 examples. During the practices you can ask any questions, after entering the formal experiment, the experimenter will not answer any questions."

4) After complete preparation experiment and ensure that participants understand the experimental requirements, recalibrate participants' eyes and enter the formal experiment, present experiment materials and eye tracker begins to record the related data, while the experimenter record participants' selection results. The eye tracker stops recording until the experiment ends.

\section{Results}

\subsection{Analysis of Virtue Products and Vice Product Selection Results}

As shown in Figure 1, when participants were asked to make an instant choice, 32.5\% chose virtue products, and a week later, $62.5 \%$ of people chose virtue products; similarly, when participants were asked to make a choice for others now, $55 \%$ of people chose virtue products, whereas make a choice for others after a week, $85 \%$ of people chose virtue products.

SPSS19.0 was used to do homogeneity of test variance for the data in Table 1. Chi-square Test revealed when consumers make choices for themselves, compared to make a choice now, under the condition of a week later, they are more inclined to choose virtue products and the difference is significant; when consumers make choices for others, compared to make a choice now, under the condition of a week later, they are more inclined to choose virtue products and the difference is significant; when consumers make choices now, compared to make a choice for themselves, under the condition of for others, they are more inclined to choose virtue products and the difference is significant; when consumers make choices a week later, compared to make a choice for themselves, under the condition of for others, they are more inclined to choose virtue products and the difference is significant.

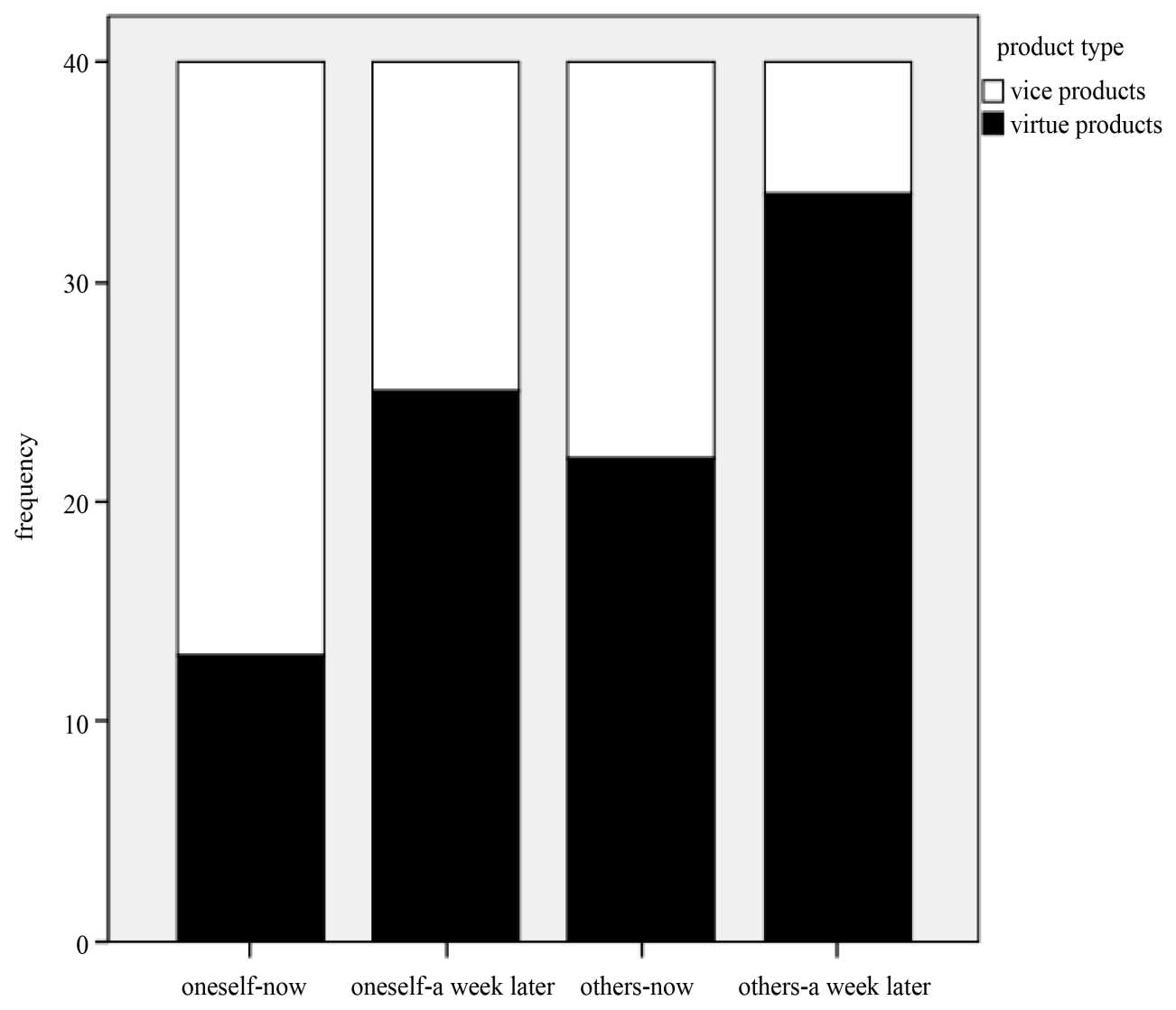

Figure 1. The choice of virtue products and vice products under different temporal distance and social distance. 
Table 1. The choice of virtue products and vice products under different temporal distance and social distance and Chisquare Test results.

\begin{tabular}{|c|c|c|c|c|c|}
\hline & Virtue products (frequency) & Vice products (frequency) & $\chi^{2}$ & df & $\mathrm{p}$ \\
\hline $\begin{array}{c}\text { Oneself now } \\
\text { Oneself a week later }\end{array}$ & $\begin{array}{l}13 \\
25\end{array}$ & $\begin{array}{l}27 \\
15\end{array}$ & 7.218 & 1 & 0.007 \\
\hline $\begin{array}{c}\text { Others now } \\
\text { Others a week later }\end{array}$ & $\begin{array}{l}22 \\
34\end{array}$ & $\begin{array}{c}18 \\
6\end{array}$ & 8.571 & 1 & 0.003 \\
\hline $\begin{array}{l}\text { Now oneself } \\
\text { Now others }\end{array}$ & $\begin{array}{l}13 \\
22\end{array}$ & $\begin{array}{l}27 \\
18\end{array}$ & 4.114 & 1 & 0.043 \\
\hline $\begin{array}{l}\text { A week later oneself } \\
\text { A week later others }\end{array}$ & $\begin{array}{l}25 \\
34\end{array}$ & $\begin{array}{c}15 \\
6\end{array}$ & 5.230 & 1 & 0.022 \\
\hline
\end{tabular}

\subsection{Analysis of Area of Interest's Eye Movement Data}

Area of interest is a basic unit of eye tracking data. In order to make further analysis to verify our experimental hypotheses, we selected the part of product name and picture as AOI1 and analysis of fixation length and fixation count for AOI1.

The average and standard deviation of fixation length on AOI1 (virtue products) under different temporal distance and social distance is shown in Table 2(a). ANOVA revealed a significant main effect of temporal distance $[\mathrm{F}(1,156)=263.354, \mathrm{p}<0.001]$, a significant main effect of social distance $[\mathrm{F}(1,156)=52.228, \mathrm{p}<0.001]$, but interaction between temporal distance and social distance was not significant $[\mathrm{F}(1,156)=0.304, \mathrm{p}=0.582]$ (see Table 2(b)).

The fixation count on area of interest AOI1 (virtue products) under different time distance and social distance is shown in Table 3(a). ANOVA revealed a significant main effect of temporal distance $[F(1,156)=294.405$, $p$ $<0.001]$, as well as social distance $[\mathrm{F}(1,156)=40.626, \mathrm{p}<0.001]$, there was no interaction between temporal distance and social distance $[\mathrm{F}(1,156)=0.137, \mathrm{p}=0.712]$ (see Table $3(\mathrm{~b})$ ).

\section{Discussion}

By the $\chi^{2}$ test of choosing frequency, the results showed that when the choice is made for oneself, the consumer preferred the virtue products currently compared with those happened after a week, and there is no significant difference at different times. Similarly, when the choice is made for others, the experiments reached the same conclusion. That is to say, either today or at some point in the future, consumers were more inclined to choose virtue products for others compared with the same choices made for their own. The difference is significant under social distance. The results confirmed our hypotheses that consumers like virtue products for others at a future time.

The ANOVA of indexes of eye movements on AOI1 (virtue products) (i.e., fixation length and fixation count) showed that main effects of time distance and social distance were significant independently, and there was not interactive action between both factors. On one hand, compared with data collected immediately, we found that the fixation length was longer and the fixation count were more frequent either for self or others to make a choice after a week. On the other hand, compared with making choice for oneself, the fixation length was also longer and the fixation count were more frequent either today or a week later to make a choice for other ones. (Appendix)

\section{Conculsion}

The study of consumer preference adopted the eyes tracking method to better understand information acquisition in decision-making process. The eye tracker can reveal the process that how individuals search for information and distribute attention. Compared with previous experimental researches, the eye tracker is a more direct and valuable measurement method which can promote decision-making process externalization. However, most of CLT researches only focused on some single-dimensional psychological effects happened under different time distance condition. Aiming at these limitations, this study tried to combine time distance with social distance, and discovered their mutual influence on consumer preferences. But we also admit the number of participants is small and can't lead to an extensive result, more participants should be provided in future study. The basic 
Table 2. (a) The average and standard deviation of fixation length on AOI1 (virtue products) under different temporal distance and social distance; (b) The analysis of variance of fixation length on AOI1 (virtue products) under different temporal distance and social distance.

(a)

\begin{tabular}{|c|c|c|c|}
\hline \multirow{2}{*}{ Temporal distance } & \multirow{2}{*}{ Social distance } & \multicolumn{2}{|c|}{ Fixation length } \\
\hline & & $M$ & $S D$ \\
\hline \multicolumn{2}{|c|}{ Now oneself } & 1.518 & 0.612 \\
\hline \multicolumn{2}{|c|}{ Now others } & 2.425 & 0.494 \\
\hline \multicolumn{2}{|c|}{ A week later oneself } & 3.474 & 0.907 \\
\hline \multicolumn{2}{|c|}{ A week later others } & 4.253 & 0.857 \\
\hline
\end{tabular}

(b)

\begin{tabular}{ccccccc}
\hline Source of variation & Sum of squares & df & MS & $F$ & Sig. \\
\hline Temporal distance & 143.232 & 1 & 143.232 & 263.354 & 0.000 \\
Social distance & 28.406 & 1 & 28.406 & 52.228 & 0.000 \\
Temporal distance* social distance & 0.165 & 1 & 0.165 & 0.304 & 0.582 \\
\hline
\end{tabular}

Table 3. (a) The average and standard deviation of fixation count on AOI1 (virtue products) under different temporal distance and social distance; (b) The analysis of variance of fixation count on AOI1 (virtue products) under different temporal distance and social distance.

(a)

\begin{tabular}{|c|c|c|c|}
\hline \multirow{2}{*}{ Temporal distance } & \multirow{2}{*}{ Social distance } & \multicolumn{2}{|c|}{ Fixation count } \\
\hline & & $M$ & $S D$ \\
\hline Now oneself & & 4.300 & 1.698 \\
\hline Now others & & 6.410 & 1.592 \\
\hline A week later oneself & & 10.200 & 2.593 \\
\hline A week later others & & 12.570 & 2.759 \\
\hline
\end{tabular}

(b)

\begin{tabular}{ccccccc}
\hline Source of variation & Sum of squares & df & MS & $F$ & Sig. \\
\hline Temporal distance & 1454.436 & 1 & 1454.436 & 294.405 & 0.000 \\
Social distance & 200.704 & 1 & 200.704 & 40.626 & 0.000 \\
Temporal distance* social distance & 0.676 & 1 & 0.676 & 0.137 & 0.712 \\
\hline
\end{tabular}

research of impact of social distance and time distance on consumer preference will enrich the relevant content about consumer decision-making by adding new variables and adopting eye tracking technology, and will provide evidences for the various theories.

\section{References}

[1] Read, D., Loewenstein, G. and Kalyanaraman, S. (1999) Mixing Virtue and Vice: Combing the Immediacy Effect and the Diversification Heuristic. Journal of Behavioral Decision Making, 12, 257-273. http://dx.doi.org/10.1002/(SICI)1099-0771(199912)12:4<257::AID-BDM327>3.0.CO;2-6

[2] Babin, B.J., Darden, W.R. and Griffin, M. (1994) Work and/or Fun: Measuring Hedonic and Utilitarian Shopping Value. Journal of Consumer Research, 20, 644-656. http://dx.doi.org/10.1086/209376

[3] Childers, T.L. Carr, C.L., Peck, J. and Carson, S. (2001) Hedonic and Utilitarian Motivations for Online Retail Shopping Behavior. Journal of Retailing, 77, 511-535. http://dx.doi.org/10.1016/S0022-4359(01)00056-2

[4] Rogers, T. and Bazerman, M.H. (2008) Future Lock-In: Future Implementation Increases Selection of "Should” Choices. 
Organizational Behavior and Human Decision Processes, 106, 1-20. http://dx.doi.org/10.1016/j.obhdp.2007.08.001

[5] Milkman, K.L., Rogers, T. and Bazerman, M.H. (2010) I’ll Have the Ice Cream Soon and the Vegetables Later: A Study of Online Grocery Purchases and Order Lead Time. Marketing Letters, 21, 17-35. http://dx.doi.org/10.1007/s11002-009-9087-0

[6] Bar-Anan, Y., Liberman, N. and Trope, Y. (2006) The Association between Psychological Distance and Construal Level: Evidence from an Implicit Association Test. Journal of Experimental Psychology General, 135, 609-622.

[7] Polman, E. (2012) Effects of Self-Other Decision Making on Regulatory Focus and Choice Overload. Journal of Personality and Social Psychology, 102, 980-993. http://dx.doi.org/10.1037/a0026966

[8] Zikmund-Fisher, B.J., Sarr, B., Fagerlin, A. and Ubel, P.A. (2006) A Matter of Perspective: Choosing for Others Differs from Choosing for Yourself in Making Treatment Decisions. Journal of General Internal Medicine, 21, 618-622. http://dx.doi.org/10.1111/j.1525-1497.2006.00410.x

[9] Jonas, E. and Frey, D. (2003) Information Search and Presentation in Advisor-Client Interactions. Organizational Behavior and Human Decision Processes, 91, 154-168. http://dx.doi.org/10.1016/S0749-5978(03)00059-1

[10] Liberman, N. and Trope, Y. (2003) Construal Level Theory of Intertemporal, Judgement and Decision. In: Read, D., Loewenstein, G. and Baumeister, R., Eds., Time and Decision: Economic and Psychological Perspectives on Intertemporal Choice, Russell Sage Foundation, New York, 245-276.

[11] Trope, Y., Liberman, N. and Wakslak, C. (2007) Construal Levels and Psychological Distance: Effects on Representation, Prediciton, Evaluation, and Behavior. Journal of Consumer Psychology, 17, 83-95. http://dx.doi.org/10.1016/S1057-7408(07)70013-X 


\section{Appendix}

The Data Sample of Participants

\begin{tabular}{|c|c|c|c|}
\hline & \multirow{2}{*}{ Participant } & \multicolumn{2}{|c|}{ AOI1 (virtue products) } \\
\hline & & Fixation length (s) & Fixation count (time) \\
\hline \multirow{10}{*}{ Now-oneself } & 1 & 1.855 & 2 \\
\hline & 2 & 1.541 & 3 \\
\hline & 3 & 0.65 & 2 \\
\hline & 4 & 1.449 & 4 \\
\hline & 5 & 1.067 & 6 \\
\hline & 6 & 1.815 & 8 \\
\hline & 7 & 1.845 & 2 \\
\hline & 8 & 2.098 & 4 \\
\hline & 9 & 1.313 & 5 \\
\hline & 10 & 2.543 & 4 \\
\hline \multirow{10}{*}{ A week later-oneself } & 1 & 3.317 & 10 \\
\hline & 2 & 4.988 & 15 \\
\hline & 3 & 4.351 & 13 \\
\hline & 4 & 2.64 & 9 \\
\hline & 5 & 3.251 & 10 \\
\hline & 6 & 4.166 & 12 \\
\hline & 7 & 4.252 & 11 \\
\hline & 8 & 2.335 & 8 \\
\hline & 9 & 2.885 & 6 \\
\hline & 10 & 3.557 & 8 \\
\hline \multirow{10}{*}{ Now-others } & 1 & 2.797 & 6 \\
\hline & 2 & 1.856 & 4 \\
\hline & 3 & 2.399 & 5 \\
\hline & 4 & 3.266 & 6 \\
\hline & 5 & 4.474 & 12 \\
\hline & 6 & 2.522 & 6 \\
\hline & 7 & 2.496 & 5 \\
\hline & 8 & 2.89 & 5 \\
\hline & 9 & 1.522 & 5 \\
\hline & 10 & 2.024 & 6 \\
\hline \multirow{10}{*}{ A week later-others } & 1 & 5.096 & 20 \\
\hline & 2 & 5.711 & 18 \\
\hline & 3 & 5.28 & 18 \\
\hline & 4 & 3.554 & 7 \\
\hline & 5 & 4.347 & 16 \\
\hline & 6 & 3.155 & 9 \\
\hline & 7 & 4.033 & 14 \\
\hline & 8 & 2.348 & 8 \\
\hline & 9 & 4.538 & 10 \\
\hline & 10 & 3.464 & 11 \\
\hline
\end{tabular}


Scientific Research Publishing (SCIRP) is one of the largest Open Access journal publishers. It is currently publishing more than 200 open access, online, peer-reviewed journals covering a wide range of academic disciplines. SCIRP serves the worldwide academic communities and contributes to the progress and application of science with its publication.

Other selected journals from SCIRP are listed as below. Submit your manuscript to us via either submit@scirp.org or Online Submission Portal.
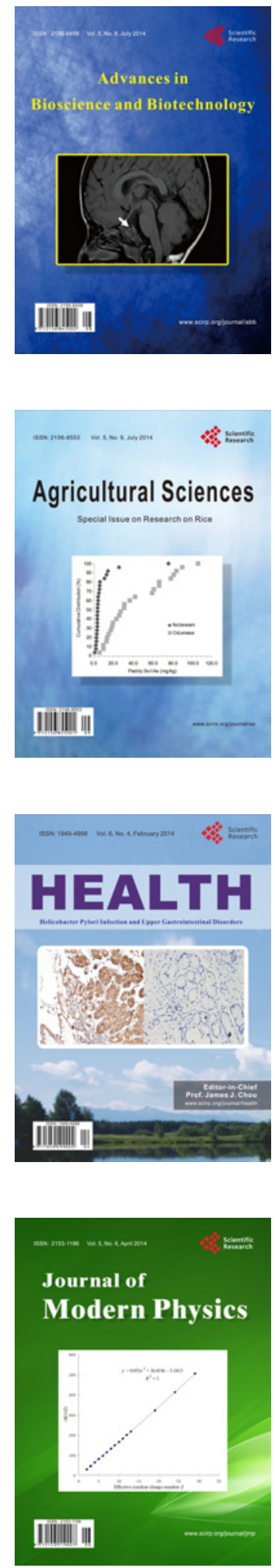
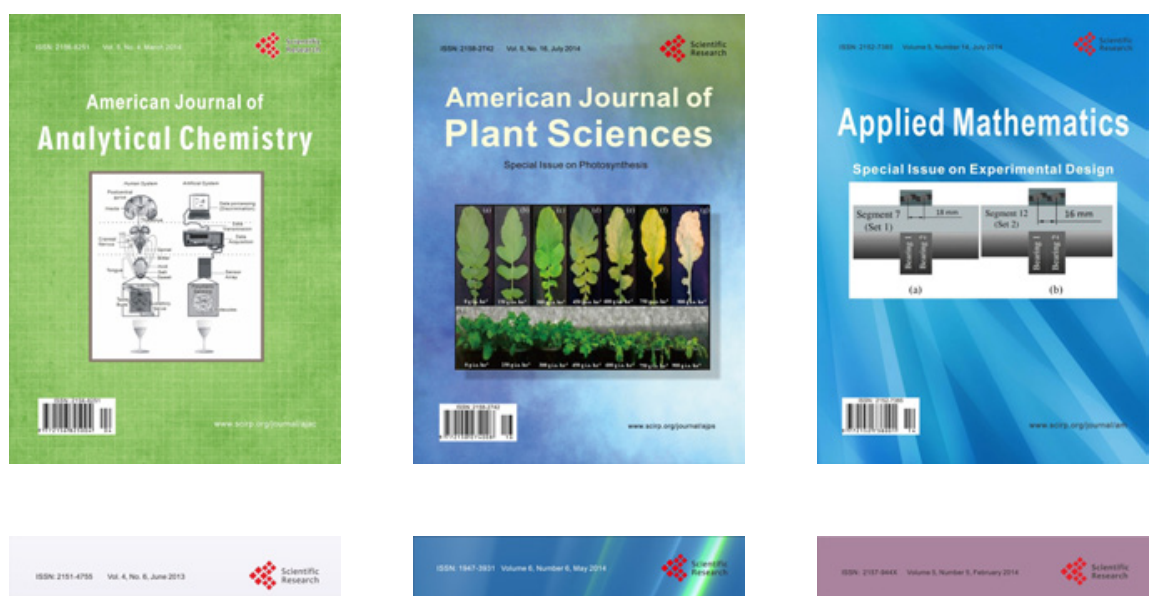

Creative Education
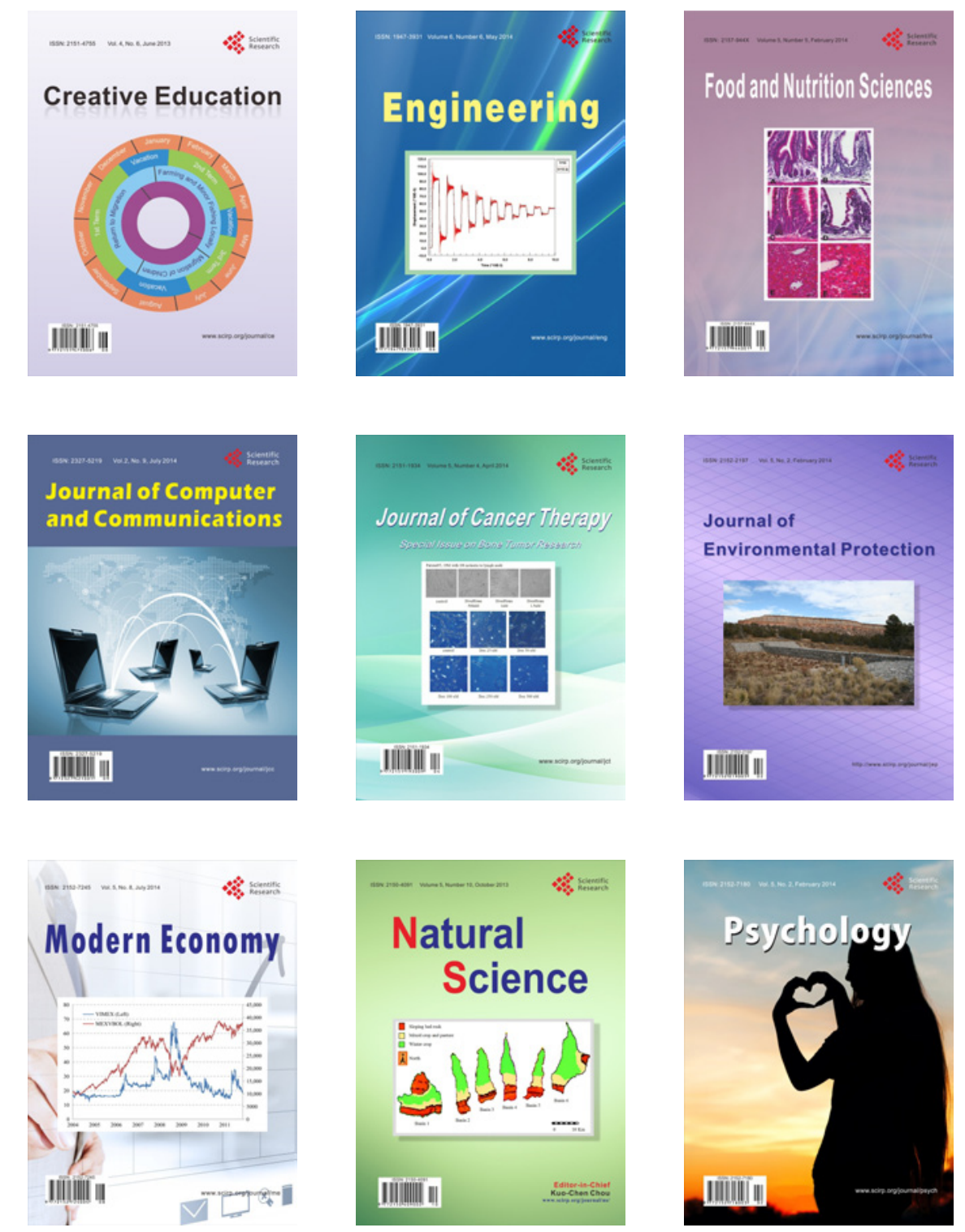